\title{
TO STUDY THE EFFECT OF YOGA EXERCISE "PRANAYAMA" BREATHING EXERCISES AND MEDITATION ON CARDIORESPIRATORY PARAMETERS IN YOUNG HEALTHY VOLUNTEERS
}

\author{
Rakesh Mohan ${ }^{1}$, Anil Kumar², Ali. Md. Ahanger ${ }^{3}$, Sanjiv Kr. Bansal4, Sonia ${ }^{5}$ \\ 1 Postgraduate Student, Department of Physiology, FMHS, SGT University, Gurgaon. \\ ${ }^{2}$ Associate Professor, Department of Physiology, FMHS, SGT University, Gurgaon. \\ ${ }^{3}$ Professor, Department of Physiology, FMHS, SGT University, Gurgaon. \\ ${ }^{4}$ Associate Professor, Department of Biochemistry, FMHS, SGT University, Gurgaon. \\ ${ }^{5}$ Assistant Professor, Department of Nursing, SGT University, Gurgaon.
}

ABSTRACT

\section{BACKGROUND}

Pranayama is a Yogic technique in which breathing is controlled voluntarily.

Aim- To study the effect of yoga exercise ("Pranayama" breathing exercise) and meditation on cardiorespiratory parameters in young healthy volunteers.

\section{MATERIALS \& METHODS}

60 healthy subjects who practised selected yogic Pranayam breathing exercises and meditation for 45 minutes daily for four months were selected for the study. The sequence of practise of the "pranayama" breathing exercise \& meditation were (1) Bhastrika,(2) Bhramari,(3) Kapalbhati,(4) Anulom-Vilom Meditation, Chanting of "OM" mantra. Heart rate, blood pressure, respiratory rate, dynamic lung function (Such as forced vital capacity, forced expiratory volume in 1 second, forced expiratory volume percentage, peak expiratory flow rate, and maximum voluntary ventilation) were measured in both groups, first at the start of study and then after the completion of four months of yogic practices.

\section{RESULTS}

Result showed significant decrease in rate of respiration, significant increase in FVC, FEV 1 MVV and PEFR, BHT \& no change in heart rate but significant decrease in SBP \& DBP.

\section{CONCLUSION}

From present study, it can be concluded that regular practise of pranayama improves respiratory as well as cardiac efficiency.

\section{KEYWORDS}

Pranayam, Heart Rate, Blood Pressure, Respiratory Rate, FVC , FEV1, Peak Expiratory Flow Rate, Maximum Voluntary Ventilation, Breath Holding Time.

HOW TO CITE THIS ARTICLE: Mohan R, Kumar A, Ahanger AM, et al. To study the effect of yoga exercise "pranayama" breathing exercises and meditation on cardiorespiratory parameters in young healthy volunteers. J. Evolution Med. Dent. Sci. 2017;6(3):235237, DOI: $10.14260 / \mathrm{Jemds} / 2017 / 54$

\section{BACKGROUND}

Yoga, derived from the Sanskrit word yuj. Yoga means union of the individual consciousness or soul with the Universal Consciousness or Spirit. It has been incorporated into modern medicine during last few decades to overcome the burden of diseases of modern civilisation such as hypertension, obesity and diabetes mellitus.

Breath is a bridge between body and mind.(1) Stresses produced during day to day can distort breathing pattern. Yogic exercises such as Pranayama help to reshape the breathing pattern and habit. Meditation provides deep rest to the system by allowing mind to calm down to its basal states. It is used for treating stress and stress-related illness.(2)

Financial or Other, Competing Interest: None.

Submission 22-11-2016, Peer Review 26-12-2016,

Acceptance 02-01-2017, Published 09-01-2017.

Corresponding Author:

Dr. Anil Kumar,

\#D-5/11, GF, Ardee City,

Sector 52, Gurgaon-122011.

E-mail: lion2ch@gmail.com

DOI: $10.14260 /$ jemds/2017/54

(c) (i) $($ ) $\Theta$
Different type of pranayama produces different cardiorespiratory responses in normal individuals. Right nostril pranayama and alternate nostril pranayama leads to increase in heart rate while left nostril pranayama decreases heart rate.(3,4) 'OM' meditation showed significant reduction in heart rate. $(5,6)$

All these studies reported the effect of individual pranayama or meditation practice. Thus, there is lack of literature regarding the latency of onset of the beneficial effects of combined practise of yoga exercise and meditation on cardiorespiratory functions. Hence, this study was designed to evaluate the outcome oft of Yoga exercises ("Pranayama" breathing exercise) and Meditation on Cardiorespiratory parameters in young healthy volunteers.

\section{MATERIALS AND METHODS \\ Materials}

This study was conducted in Department of Physiology, SGT Medical College Hospital \& Research Institute (Faculty of Medicine \& Health Sciences), SGT University, District Gurgaon, Haryana. The ethical clearance was taken for the study from the Ethical Committee of the Institute. 60 subjects of both sex, from SGT Campus were selected for the study, subject to the criteria described below. Consent was taken from the subjects prior to involving in the study on a consent form. 


\section{Inclusion Criteria}

Healthy subjects from SGT campus were included in the study.

\section{Age Group}

17 to 25 years.

\section{Exclusion Criteria}

- Subjects with known hepatic, renal, haematological or any organ disorder.

- Subjects on any long term medication or drugs.

- Smokers and alcoholics.

- Subject already practising Yoga.

\section{Methods}

60 healthy subjects were selected for the study who practised selected yogic Pranayam breathing exercises and meditation for 45 minutes daily, for four months.

Heart rate, blood pressure, respiratory rate, dynamic lung function (Such as forced vital capacity, forced expiratory volume in 1 second, peak expiratory flow rate, and maximum voluntary ventilation) were measured in both groups first at the start of study and then after the completion of four months of yogic practices.

The sequence of practise of the "pranayama" breathing exercise \& meditation are explained below.

\section{Sequence of Yogic Pranayam Practices Pranayama}

1. Bhastrika (Forceful expulsion of breath) -2 minutes.

2. Bhramari (Producing buzz sound of bee with closed ears and lips)-5 times.

3. Kapalbhati-10 minutes.

4. Anulom-Vilom (Alternate nostril breathing)-15 times.

\section{Meditation}

Chanting of "OM" mantra for $10 \mathrm{~min}$.

The heart rate (HR) was measured by counting radial pulse by palpatory method. Blood pressure was measured using an arm mercury sphygmomanometer.

The respiratory rate (RR) was counted while the subjects lying in the supine position. Dynamic lung functions- forced vital capacity (FVC), forced expiratory volume in 1 second (FEV1), peak expiratory flow rate (PEFR), and maximum voluntary ventilation (MVV) was studied with the help of a computer-automated spirometer.

\section{Following Cardiorespiratory Parameters were studied}

- Heart rate (HR).

- $\quad$ Blood Pressure- Systolic \& diastolic (SBP, DBP).

- $\quad$ Respiratory rate (RR).

- $\quad$ Tidal Volume (TV).

- $\quad$ Forced Expiratory Volume in first second (FEV 1 )

- Breath holding time (BHT).

- Maximum Voluntary ventilation.

- Peak expiratory flow rate.

\section{Statistical Analysis}

The results were analysed by using statistical software statistical package of social sciences (SPSS).

\section{RESULTS}

Result showed significant decrease in rate of respiration, significant increase in FVC, FEV 1 MVV and PEFR, BHT \& no change in heart rate but significant decrease in SBP \& DBP.

\begin{tabular}{|c|c|c|c|}
\hline Variables & $\begin{array}{c}\text { Before } \\
\text { (mean } \pm \text { SD) }\end{array}$ & $\begin{array}{c}\text { After } \\
\text { (mean } \pm \text { SD) }\end{array}$ & P value \\
\hline FVC (L/min.) & $2.65 \pm 0.40$ & $3.21 \pm 0.40$ & $<0.001^{* *}$ \\
\hline FVC1 (L/min.) & $2.34 \pm 0.35$ & $2.99 \pm 4.0$ & $<0.001^{* *}$ \\
\hline PEFR (L/min.) & $6.10 \pm 1.06$ & $7.23 \pm 3.2$ & $<0.001^{* *}$ \\
\hline BHT (sec) & $36.82 \pm 4.29$ & $54.71 \pm 8.01$ & $<0.001^{* *}$ \\
\hline MVV (litres) & $102.6 \pm 11.7$ & $129.5 \pm 16.4$ & $<0.001^{* *}$ \\
\hline RR (per/min.) & $18.2 \pm 2.4$ & $17.4 \pm 1.2$ & $<0.001^{* *}$ \\
\hline HR (per/min.) & $70.6 \pm 10.12$ & $70.5 \pm 10.01$ & $>0.005^{* *}$ \\
\hline SBP (mm/Hg) & $120.2 \pm 6.14$ & $111.4 \pm 6.18$ & $<0.001^{* *}$ \\
\hline DBP (mm/Hg) & $72.4 \pm 6.06$ & $66.82 \pm 5.6$ & $<0.001^{* *}$ \\
\hline \multicolumn{4}{|c|}{$\begin{array}{c}\text { Effect of Yoga Pranayama and Meditation } \\
\text { on Cardiopulmonary Functions }\end{array}$} \\
\hline
\end{tabular}

\section{DISCUSSION}

The significant decrease in systolic and diastolic blood pressure after the yoga practice in the present study is in accordance with finding of other studies on physiological effect of yoga practice in healthy individual.(7) The present study demonstrates that regular practise of yoga exercise and meditation causes alteration in autonomic balance of cardiorespiratory function and well-being. Pranayama is reported to improve breathing rate and ventilator functions of the lung. ${ }^{(8)}$

There was significant decrease in respiratory rate \& increase in FVC, FEV 1 , MVV and PEFR. Similar observations has been recorded by other research workers. ${ }^{(9,10,11,12,13,14)}$ Most of the effects may be due to strengthening of muscles of respiration due to regular practise of pranayamic breathing during which the lungs and chest inflate and deflate to fullest possible extent and muscles are made to work to maximal extent.(15) Secondly, lung inflation near to total lung capacity is a major physiological stimulus for release of lung surfactant(15) and prostaglandins into alveolar spaces,(16) which increase lung compliance and decrease bronchiolar smooth muscle tone, respectively.(11)

There was significant increase in BHT which may be due to decreased responsiveness to carbon dioxide to respiratory centre or chemoreceptor. There may also be hypometabolic state of the body characterised by decreased $\mathrm{CO}_{2}$ production and decreased oxygen consumption, thus allowing breath holding for a longer time.

In the present study, significant reduction in SBP and DBP can be attributed to modulation of autonomic activity with parasympathetic predominance and relatively reduced sympathetic tone. This autonomic modulation in yoga is mediated through modification of breathing patterns which triggers various central and autonomic mechanisms as well as mechanical and haemodynamic adjustments causing both tonic and phasic changes in cardiovascular functioning. ${ }^{17)}$ Similar findings have been reported by other workers. $(12,13,14,18,19,20)$

\section{CONCLUSION}

The present study suggests that regular practise of Yoga Pranayama and Meditation can bring significant improvement in the autonomic balance and respiratory performance (as 
shown by increase in FVC, FEV1\%, PEFR, MVV and increase in tolerance to $\mathrm{CO} 2$ as shown by prolonged $\mathrm{BHT}$ and decrease in respiratory rate, decrease in systolic and diastolic blood pressure). Thus, we conclude that daily practise of Yoga Pranayama and Meditation will improve the quality of life by improving cardiopulmonary functions.

\section{REFERENCES}

[1] Bijlani RL. Understanding medical physiology. $3^{\text {rd }}$ edn. New Delhi: Jaypee Brothers 2004:871-910.

[2] Nagarathna R, Nagendra HR. Bangalore: Swami Vivekanand Yoga Prakashana. $4^{\text {th }}$ edn. Yoga for promotion of positive health 2006.

[3] Shannahoff-Khalsa DS, Kennedy B. The effects of unilateral forced nostril breathing on heart. Int J Neurosci 1993;73(1-2):47-60.

[4] Varun M, Tandon OP, Rajkumar P, et al. Suryanadi anuloma viloma pranayama modifies autonomic activity of heart. J Yoga Spring 2009;8(1).

[5] Telles S, Nagarathna R, Nagendra HR. Breathing through a particular nostril can alter metabolism and autonomic activities. Indian J Physiol Pharmacol 1994;38(2):133-7.

[6] Telles S, Nagarthana R, Nagendra HR. Autonomic changes during ' $\mathrm{OM}$ ' meditation. Indian $\mathrm{J}$ Physiol Pharmacol 1995;39(4):418-20.

[7] Bharshankar JR, Bharshankar RN, Deshpande VN, et al. Effect of yoga on cardiovascular system in subjects above 40 years. Indian J Physiol Pharmacol 2003;47(2):202-6.

[8] Yadav RK, Das S. Effects of yogic practice on pulmonary functions in young females. International Journal of Physiology 2001;45(4):493-6.

[9] Bhargava R, Gogate MG, Mascarenhas JF. Autonomic responses to breath holding and its variations following pranayama. Ind J Physiol Pharmac 1988;32(4):257-64.

[10] Dinesh T, Gaur GS, Sharma VK, et al. Effect of 6 weeks of Kapalbhati pranayama training on peak expiratory flow rate in young healthy volunteers. Sch Acad J Biosci 2013;1(4):112-4.
[11] Joshi LN, Joshi VD, Gokhale LV. Effect of short term 'Pranayam' practice on breathing rate \& ventilatory functions of lung. Indian $\mathrm{J}$ Physiol Pharmacol 1992;36(2):105-8.

[12] Danucalov MA, Simoes RS, Kozasa EH, et al. Cardiorespiratory and metabolic changes during yoga sessions: the effects of respiratory exercises and meditation practices. Appl Psychophysiol Biofedback 2008;33(2):77-81.

[13] Harinath K, Malhotra AS, Pal K, et al. The effect of hatha yoga and omkar meditation on cardiorespiratory performance, psychologic profile and melatonin secretion. J Alternative Complementary Medicine 2004;10(2):261-8.

[14] Shankarappa V, Prashanth P, Annamalai N, et al. The short term effect of pranayama on the lung parameters. J Clinical \& Diagnostic Research 2012;6(1):27-30.

[15] Hildebran JN, Georke J, Clemens JA. Surfactant release in exercised rat lung is stimulated by air inflation. J Appl Physiol Respir Environ Exerc Physiol 1981;51(4):90510.

[16] Smith AP. Prostaglandins and respiratory systemphysiological, pharmacological and pathological aspects. J Appl Physiol 1976;5:83-102.

[17] Raghuraj P, Ramakrishnan AG, Nagendra HR, et al. Effect of two selected yogic breathing techniques of heart rate variability. Indian J Physiol Pharmacol 1998;42(4):467-72.

[18] Kanojia S, Sharma VK, Gandhi A, et al. Effect of yoga on autonomic functions and psychological status during both phase of menstrual cycle in young healthy females. Journal of Clinical and Diagnostic Research 2013;7(10):2133-9.

[19] Satyanand V, Reddy B, Lilly N, et al. Studying the role of yogic pranayama in the management of blood pressure. Int J of Biomed \& Advance Res 2014;5(12):609-11.

[20] Sivananda SS. Introduction to pranayama. The Science of Pranayama 1997;16:26-7. 